\title{
Litigation and settlement in patent infringement cases
}

\author{
Claude Crampes* and Corinne Langinier ${ }^{\dagger}$
}

February 2002

\begin{abstract}
A patent is not a perfect protection against imitation. It only grants the patentholder the right to sue intruders once they have been identified. This implies that the patentholder must supervise the market and react in case of infringement. His reaction may be to go to court, to settle an agreement or to accept the entry. We investigate how intensive the monitoring effort should be and how it will influence the entry decision. In a simultaneous game we show that even if the penalty paid by the infringer in case of a finding of liability is high, the patentholder may prefer a settlement over a trial. Furthermore, there exist cases in which the likelihood of entry increases with the penalty. In sequential games, we show that regardless of whether the patentholder or the potential infringer plays first, entry occurs comparatively less often than in the simultaneous game.
\end{abstract}

Keywords: Patent, Infringement, Settlement, Trial.

JEL Classification $=\mathrm{K} 41, \mathrm{O} 34, \mathrm{~L} 13$.

*Toulouse University,GREMAQ and IDEI; crampes@cict.fr

${ }^{\dagger}$ Iowa State University, Ames; langinier@econ.iastate.edu

We would like to thank seminar and conference participants at the University of Laval (Quebec), Perpignan (France), CEA 2000 (Vancouver), JMA 2000 (Quebec), CEPR/ZEW 2000 (Mannheim) and CERNA 2001 (Paris). We are indebted to two anonymous referees and a co-editor of the journal for helpful comments. We are responsible for remaining errors. 


\section{Introduction}

Lawyers often justify patents by a simple backward-looking argument: innovators deserve at least to recoup their $\mathrm{R} \& \mathrm{D}$ expenses, and patents are a good tool to accomplish this. In contrast, economists insist on the forward-looking incentive feature of patents. An innovator will direct his R\&D efforts to those markets which are seen as being profitable in the future thanks to patent protection. The problem with this prospective viewpoint is that a patent becomes more than a mere reward for the innovator. It may also reward high performance in production and marketing. With the same patent, two different firms could obtain different benefits due to having different production and merchandising capabilities. ${ }^{1}$

But this point of view is still too narrow because a patent is not a perfect protection against entry. It merely grants a right to sue intruders. If the patentholder cannot observe infringement, if he cannot identify the infringer, or if enforcement is too costly, the patent is undermined. This means that the value of a patent strongly depends both ex ante, when designing the patent claims and ex post, when enforcing them, on the competency of the innovator's legal department or on the quality of external legal advisers. ${ }^{2}$ It follows that while patents are typically viewed in the economic literature as a perfect exogenously given protection against imitation, ${ }^{3}$ their efficiency depends on their idiosyncratic characteristics and on the effort of the patent owner in trial and settlement procedures.

When an innovator applies for a patent, there is some probability that one or several firms active in the market will try to impede him from monopolizing a fraction of this market. Accordingly patent-invalidity suits are one possible consequence of patent applications and they can be dissuasive for candidates to patent. ${ }^{4}$ In this paper, we do not analyze this issue. We rather limit our study to patent infringements, that is to situations where the roles are reversed as compared to invalid patents. Here, the property rights of the patentholder are not questionable and consequently he

\footnotetext{
${ }^{1}$ This explains why a good innovator who is also a bad developer has strong incentives to license his innovations.

2 "Unless one is willing to sue on it, a patent is virtually useless, just a fancy piece of paper with a gold seal that looks good on the wall" (H.L. Speight, The National Law Journal, Monday, June 22, 1998).

${ }^{3}$ Gallini (1992) is an exception since she explicitly models the possibility of imitation. Note also that patents can have adverse effects: by signalling market profitability, they can increase the probability of entry instead of reducing it (see Crampes and Langinier, 1998).

${ }^{4}$ Similarly, the opposition mechanism, designed by the European Patent Office, "can be considered as an early form of litigation in which opponents may argue that a patent grant issued by EPO should be either revoked or amended", Harhoff and Reitzig (2000). Meurer (1989) studies patent licensing in the settlement of litigation when the patent is potentially invalid.
} 
can sue any newcomer.

Most economic papers on patents focus on the ex ante decisions of R\&D processes: How much to invest in research or development? (Reinganum, 1989); Is it worthwhile to apply for a patent? (Aoki and Spiegel, 2000); Should the patent claims be for narrow (short) or wide (long) applications? Or, in other words, what should be the breadth (length) of the patent? (Klemperer, 1990; Gilbert and Shapiro, 1990). By contrast, we consider the case of a firm that is already a patent owner, and we deal with the following ex post problems: how intensively should patent-protected markets be watched and what is the best reaction to infringement? Indeed, the monitoring effort is all but routine. "By day, dressed in business suits, Flack and Whybrow (two very famous fraud investigators) posed as "procurement agent" seeking drug samples from suspect manufacturers; the samples would then be analyzed to see whether patents have been violated. By night the really dangerous work began: The pair would don dark clothes and leap over factory walls -taking photographs, rummaging through garbage bins, ripping labels off containers, and sometimes even entering the plants themselves" (Fortune, Drug Spies, September 6, 1999). Even if this is an extreme case of monitoring and at the edge of legality, it shows how important monitoring is.

We consider a static game in which the patentholder and the infringer decide respectively on the intensity of monitoring and whether or not to enter the protected market. If imitation occurs, the patentholder may attempt to establish the identity of the infringer and to conduct investigations concerning her. If he succeeds, the patentholder can choose between several options. He may decide to sue the infringer, to try to reach a settlement or eventually to abandon any pursuit and let the infringer remain in the market. Each of these outcomes is costly. To let the infringer stay in the market reduces market power. To go to court involves trial expenses. And to settle an agreement involves settlement costs and market sharing.

We first define different equilibrium sets depending on these costs. Going backward we then study the monitoring effort of the patentholder and the entry decision of the challenger when they take their decision simultaneously. We show how the equilibrium changes after variations in the parameters of the model. In particular, we show that the likelihood of entry may locally increase with the penalty for infringement. We also prove that the frequency of infringement increases with the profit differentials, decreases with the efficiency of the legal procedure and the probability of identification. When the settlement cost and the bargaining power of the patentholder increase the effect on entry is ambiguous. All the results are summarized in a graph.

We then consider two alternative sequential games. In the first game, the patentholder takes 
his monitoring decision first while in the second game the infringer is the leader on entering or not. We show that in these sequential games, entry occurs comparatively less often than in the simultaneous game and the patentholder is always better off in the sequential setting.

Patent is not the only tool to deter entry. Patent scope can manifestly be designed to discourage entry. Broad and short patents can be designed to discourage imitation (Gallini, 1992), but licensing and threat of litigation can also potentially serve as entry deterrence. Indeed, licenses can discourage potential entrants to develop a possibly better technology as shown by Gallini (1984). Furthermore, as the patent protection is not perfect, litigation and settlement are important elements of patent cases. In a non-cooperative game approach, the litigation process can be seen as an opportunity to engage in strategic behavior when the validity of the patent can be challenged in court (Meurer, 1989). In this case a trial is just a failure to settlement and not a deliberated choice. On the other hand, in a cooperative approach to litigation and settlement, a trial can be Pareto efficient (Aoki and $\mathrm{Hu}, 1999)$, and the threat of litigation can deter entry. We argue that monitoring moves the threat forward (in time) and serves as entry deterrence.

The paper is organized as follows. In section 2, we present the hypotheses and the timing of the model. In section 3, we analyze the last stage of the game where the patentholder has to decide what to do when he identifies an infringer. In section 4, we exhibit the equilibria of the game where the patentholder decides how much to spend in monitoring activities while simultaneously a challenger decides whether or not to enter the protected market. It also includes a graphical illustration and a discussion of the effect on entry of variations in the parameters underlying the simultaneous game. In section 5, we consider the effects of sequentiality. We first assume that the challenger knows the monitoring effort of the incumbent before deciding on entry and then we analyze the opposite timing. Section 6 concludes.

\section{Model setting}

Consider two players, labeled $h$ for the patentholder and $i$ for the potential infringer. At the beginning of the game, an innovation has already been patented. The owner has to decide whether or not to invest in efforts to detect the possible entry of an imitator and to identify her. If no entry has occurred (denoted by $e=0$ ), the patentholder earns monopoly profits $\pi_{m}^{h}$ and the potential infringer receives 0 . We assume that the incumbent always detects entry because he can observe a decrease in his profits due to the presence of a competitor. However, detection is not sufficient 
for a settlement or a lawsuit. In order to propose a settlement or to threaten an entrant with going to court it is necessary $(i)$ to establish the identity of the infringer, $(i i)$ to check the validity of the patent and (iii) to check whether there are meaningful arguments of infringement. ${ }^{5}$ All these expenditures are summed up in the "monitoring effort" $x$. If entry has occurred $(e=1)$, the infringer is identified by the patentholder with probability $p(x)$. We assume that $p^{\prime}(x)>0$, $p^{\prime \prime}(x)<0, p(0)>0$ and there exists $\bar{x}$ such that $p(\bar{x})=1$. In our setting the entry decision is purely dichotomic. This means that the size of the market(s) protected by the patent is irrelevant. Actually since the patentholder has designed the patent to take account of the breadth of the protection, a more complex decision function would be more realistic. Moreover, because with a broader protection the identification of infringers is harder, the function $p(x)$ could be negatively correlated with the patent breadth.

When the patentholder identifies the imitator and thinks he can claim for infringement, he considers one of the three following endings:

$(R)$ to accept the entry without any reaction: we call it the "renunciation solution";

$(S)$ to come to some kind of arrangement with the entrant: the "settlement solution";

$(T)$ to sue the infringer at law: the "trial solution".

Except in case $(T)$ when the plaintiff succeeds in obtaining an injunction requiring the infringer to stop making and selling the product based on the patented innovation, the resulting market structure is a duopoly. In case $(R)$, the gross profit of the incumbent is $\pi_{d}^{h} \leq \pi_{m}^{h}$ and the entrant obtains a net profit equal to $\pi_{d}^{i}$. If the challenger markets a highly differentiated product, it is quite possible to have $\pi_{d}^{h}$ close to $\pi_{m}^{h}$ despite $\pi_{d}^{i}>0$. On the contrary, with an imitator selling a close substitute in the same market, we obviously have $\pi_{d}^{h}+\pi_{d}^{i}<\pi_{m}^{h}$.

Consider now the trial outcome $(T)$ where the patentholder decides to go to court when the imitator is identified. This solution has several drawbacks. ${ }^{6}$ First, it can be bad publicity for both firms. Most managers and shareholders prefer to see the name of their firm or brand in business news rather than under judicial headlines. For this reason, we can assume that the profit in the

\footnotetext{
${ }^{5}$ In the famous case of Polaroid versus Eastman Kodak, out of 12 initial patent infringement charges, the judge found Kodak had infringed seven valid Polaroid patents. Two patents were found invalid and one was found not infringed. Before trial, Polaroid withdrew its claims on one patent and another was found invalid.

${ }^{6}$ For an econometric analysis of the determinants of litigation to resolve disputes on patents, see Lanjouw and Schankerman (1998), and Lanjouw and Lerner (1997) for a survey of the empirical literature.
} 
trial case is smaller or equal to the profit in case of renunciation. Formally, $\widetilde{\pi}_{d}^{h} \leq \pi_{d}^{h}$ is the profit for the incumbent and $\widetilde{\pi}_{d}^{i} \leq \pi_{d}^{i}$ for the entrant. ${ }^{7}$ The second disadvantage is that a trial is both costly and risky. The plaintiff cannot be sure from the very beginning whether the defendant will be found to have infringed. ${ }^{8}$ If $F_{t}$ is the expected fine to be paid in the trial case, the payoff of the infringer is $\tilde{\pi}_{d}^{i}-F_{t}$. The expected net compensation received by the plaintiff (gross compensation minus lawyers' retainer and proceeding expenditures) is $\alpha F_{t}$ where $\alpha$ is a number between 0 and 1 , a proxy for the efficiency of the legal procedure. We assume that damages are a fraction of the penalty, like in Lanjouw and Lerner (1997), and that the patentholder does not receive the whole penalty, because of the procedure fees and lawyers' retainers. An extreme case is considered in Aoki and $\mathrm{Hu}(1999 \mathrm{~b})$, where $\alpha=1$. In any case, the net payoff of the patentholder when choosing the trial solution is $\widetilde{\pi}_{d}^{h}+\alpha F_{t}$.

Given this assumption of proportional remedy, we are left with the problem of fixing the fine $F_{t}$. We can imagine that the compensation must be exactly equal to the loss associated with a duopoly situation instead of a monopoly $\left(\pi_{m}^{h}-\widetilde{\pi}_{d}^{h}\right) \cdot{ }^{9}$ In this case, the penalty for the imitator becomes $F_{t}=\left(\pi_{m}^{h}-\tilde{\pi}_{d}^{h}\right) / \alpha$. If the infringer is willful, the court can increase damages up to three times the actual ones. It can also occur that the losing party is required to pay the legal fees of the winning party. ${ }^{10}$ To remain as general as possible, we keep the penalty as a variable parameter which obviously includes the former particular cases.

But a trial also has valuable advantages for the plaintiff: for instance, a judicial conviction of the patent violator allows the stopping of unfair competition, gaining damages, and drastically reducing the risk of future infringement by designing around the patent. As mentioned by Lanjouw and Lerner (1997), there is a substantial degree of stake asymmetry. ${ }^{11}$ If the patentholder is more

\footnotetext{
${ }^{7}$ These profits represent the expected discounted payoffs in case of trial. Actually when the patentholder wins the case, he may have a new monopoly position if the infringer has to exit the market. Here, we just assume that the expected discounted payoffs will be smaller than the monopoly payoffs. There exists evidence that a trial reduces the profit of the firms (Lerner, 1995)).

${ }^{8}$ For the patent owner, uncertainty on the benefits of a trial is examined in Choi (1998), Pooley (1999) and Silverman (1992).

${ }^{9}$ The Polaroid vs. Kodak case is a good example: "Kodak was to pay Polaroid $\$ 454$ million in compensation for the 10 years its instant products were on the market. An additional $\$ 455$ million was added on as interest" (Warshofsky, 1994). For an analysis of alternative doctrines of damages, see Schankerman and Scotchmer (2001).

${ }^{10}$ This is the common rule in the British system. In the US each party in patent litigation pays its own legal fees except in case of willful infringement (Meurer, 1989; Aoki and Hu 1999a and 1999b). For example, "Polaroid's request for treble damages for willful infringements by Kodak were denied by the judge" (Warshofsky, 1994).

${ }^{11}$ In the vast majority of patent infringement suits, the stakes far exceed $\$ 50,000$ (survey from the American
} 
likely than the potential infringer to play repeatedly, his stake will be higher. There is an obvious reputational effect. Here, we consider that legal fees are included in $\alpha$ and $F_{t}$, and that the infringer will pay more for the damage than what the patentholder will receive. Note also that, depending on technology areas, some patents are easier to defend than others. For example, using patent data from West Germany, Lanjouw (1993) shows that engine patents are the most difficult to defend, followed by computer patents. Textile patents as well as pharmaceutical patents are more easily defended.

Finally, the patentholder can propose a settlement to the infringer $(S)$. The choice of a settlement over a trial strongly vary among industries. For instance in the computer industry, business agreements seem to be preferred to legal wars by contrast with the biotechnology industry. IBM does not have a history of litigation to protect its patents in court. In most cases the agreement is a license contract allowing the sharing of the benefits derived from the use of the patented innovation. We assume that such an initiative is costly for the patentholder because of the preparation of the technical files and some likely adaptation of the innovating process or product. In a dynamic bargaining framework, we should add the costs associated with the number and duration of negotiation rounds. These costs would penalize both parties and would affect the surplus to be shared. Because our model is static we only have to consider the cost incurred by the patentholder to launch the negotiation. After this cost is paid by the patentholder, both players begin a bargaining process in order to determine how they share the profit. We assume that the outcome of this process is given by the Nash bargaining solution ${ }^{12}$. Consequently, we must begin by assessing the alternative utility for both players, that is how much they are sure to earn if the negotiation fails. Since the initiative is taken by the patentholder, the reservation values to take into account are the pair of gains corresponding to his highest alternative payoff.

The framework we use to analyze the post patenting battles is a two-stage game.

- In the first stage the potential entrant decides whether to enter or not and the patentholder decides whether to commit to a certain level of supervision. In section 4, we assume that the decisions are simultaneous while in section 5 they are sequential.

- In the second stage, if entry has occurred and the identity of the infringer has been discovered, Intellectual Property Association, 1995).

${ }^{12}$ Nash bargaining is also used by Aoki and $\mathrm{Hu}$ (1999a, 1999b). For a survey concerning the economic analysis of legal disputes in a general framework see Cooter and Rubinfeld (1989). For a survey on settlement in patent dispute see Lanjouw and Lerner (1997). 
the patentholder may decide to react to the infringement. In this subgame, he is the only decision maker, and he decides whether to settle out of court, to go to court or to let the infringer compete in the market.

In order to determine the equilibria by backward induction, we begin by determining the best decision of the patentholder in the second stage of the game.

\section{To Settle or Not To Settle?}

Suppose that entry has occurred and the patentholder has clearly identified the infringer. Shall he go to court, settle or accept the illegal entry?

Assume first that $\pi_{d}^{h}>\tilde{\pi}_{d}^{h}+\alpha F_{t}$. Hence the reservation values in the negotiation round will be the respective profits corresponding to outcome $(R), \pi_{d}^{h}$ for the incumbent and $\pi_{d}^{i}$ for the entrant. Since we are in a negotiation without any risk of trial in case of failure, if $L$ denotes the amount of the fee for the use of the patent, the gross profits are respectively $\pi_{d}^{h}+L$ for the incumbent and $\pi_{d}^{i}-L$ for the entrant. Hence the net profit from bargaining is equal to $L$ for the patentholder and $-L$ for the imitator. In other words, it is a zero-sum game and there is nothing to share so that the settlement process is not a mutually profitable alternative to the renunciation solution. Note that we obtain this outcome under the implicit assumption that the parties cannot take advantage of the negotiation to collude and maximize joint profits due, for example, to a very strict antitrust policy.

Suppose on the contrary that $\pi_{d}^{h}<\widetilde{\pi}_{d}^{h}+\alpha F_{t}$. Now the incumbent prefers to sue the infringer rather than to accept her entry without any reaction. The term on the right-hand side of the above inequality is the patentholder's reservation value in the bargaining process and, consequently, the reservation value of the infringer is $\tilde{\pi}_{d}^{i}-F_{t}$. Hence, the judicial procedure is the "backup solution" for settlement. ${ }^{13}$ It results that the licence fee will be calculated as the solution of

$$
\max _{L}\left(\pi_{d}^{h}+L-\widetilde{\pi}_{d}^{h}-\alpha F_{t}\right)^{\rho}\left(\pi_{d}^{i}-L-\widetilde{\pi}_{d}^{i}+F_{t}\right)^{1-\rho}
$$

where $\rho \in(0,1)$ measures the relative negotiation power of the patentholder. From the first order

\footnotetext{
${ }^{13}$ The same hypothesis is used by Lanjouw and Lerner (1997). Among numerous examples, one can quote Michael Green (Lucent president of intellectual property): "After numerous attempts to negotiate with Cisco, we were left with no other recourse but to file suit", or an analyst at Lehman Brothers: "These things usually get settled out of court.” CNN, June 19, 1998. See also Marshall, Meurer, and Richard (1994).
} 
condition, the licence fee obtained in the negotiation round is

$$
L^{*}=\rho\left[\pi_{d}^{i}-\widetilde{\pi}_{d}^{i}+F_{t}\right]+(1-\rho)\left[\widetilde{\pi}_{d}^{h}+\alpha F_{t}-\pi_{d}^{h}\right]
$$

and consequently, the gross profits of the players in the settlement solution are respectively

$$
\begin{aligned}
& \Pi^{h}=\pi_{d}^{h}+L^{*}=\rho\left[\pi_{d}^{h}+\pi_{d}^{i}-\tilde{\pi}_{d}^{i}+F_{t}\right]+(1-\rho)\left[\tilde{\pi}_{d}^{h}+\alpha F_{t}\right] \\
& \Pi^{i}=\pi_{d}^{i}-L^{*}=(1-\rho)\left[\pi_{d}^{i}+\pi_{d}^{h}-\widetilde{\pi}_{d}^{h}-\alpha F_{t}\right]+\rho\left[\tilde{\pi}_{d}^{i}-F_{t}\right]
\end{aligned}
$$

The transfer from the infringer to the patentholder (licence fee) is increasing with the value of the fine paid by the infringer and decreasing with the loss associated with the trial for the patentholder. This is consistent with the results of Aoki and $\mathrm{Hu}$ (1999a). The profit of the patentholder (respectively the infringer) is obviously increasing with his (resp. her) negotiation power $\rho$ (resp. $1-\rho$ ). With regard to the infringer, she will be more inclined to negotiate when the fine $F_{t}$ and damages $\alpha F_{t}$ are not too high. As compared with the lawsuit outcome, bilateral negotiation allows both parties to save legal expenses. For the entrant, an extra advantage of the settlement procedure is to extinguish claims for prior infringement. For the patentholder, information disclosure is easier to control.

To sum up, when he can identify an entrant, the best decision of the patentholder (to accommodate, to settle or to sue the infringer) depends on the relative values of the three gross profits ${ }^{14}$ $\pi_{d}^{h}, \tilde{\pi}_{d}^{h}+\alpha F_{t}$ and $\Pi^{h}-F_{s}$ where $F_{s}$ denotes the settlement cost.

The following proposition describes the frontiers of the three solutions:

Proposition 1 When $\pi_{d}^{h}>\widetilde{\pi}_{d}^{h}+\alpha F_{t}$, the patentholder will renounce to sue or to settle. When $\pi_{d}^{h}<\tilde{\pi}_{d}^{h}+\alpha F_{t}$, if $F_{s} \geq \rho(1-\alpha) F_{t}+\rho\left(\pi_{d}^{h}-\tilde{\pi}_{d}^{h}+\pi_{d}^{i}-\tilde{\pi}_{d}^{i}\right)$ the patentholder will go to court, and he will settle otherwise.

Proof. To show the first part of proposition 1, note that if $\pi_{d}^{h}>\widetilde{\pi}_{d}^{h}+\alpha F_{t}$ is satisfied before to decide between $(R),(S)$ and $(T)$ it remains true after. The consequence is that if the patentholder chooses to settle and if the settlement fails, he will not go to court. He will just accept entry and earn a duopoly profit. Therefore, the net gains of the patentholder from a settlement are $\Pi^{h}-F_{s}=\pi_{d}^{h}-F_{s}<\pi_{d}^{h}$.

\footnotetext{
${ }^{14}$ To obtain the net final profit, it remains to substract the monitoring expenditure $x$.
} 
To show the second part of the proposition, we just have to compare the profit from a trial, that is $\widetilde{\pi}_{d}^{h}+\alpha F_{t}$, with the profits from a settlement, namely $\Pi^{h}-F_{s}$ where $\Pi^{h}$ is given by the relation (2). Q.E.D.

To illustrate proposition 1, one can refer to Figure 2 where we have drawn as heavy lines the pairs $\left(F_{s}, F_{t}\right)$ that make the incumbent indifferent between $(R),(S)$ and $(T)$.

The frontier between renunciation on one hand and trial and settlement on the other hand is given by the vertical line

$$
F_{t}=\frac{\pi_{d}^{h}-\tilde{\pi}_{d}^{h}}{\alpha}
$$

Indifference between settlement and trial is defined by

$$
F_{s}=\rho(1-\alpha) F_{t}+\rho\left(\pi_{d}^{h}-\tilde{\pi}_{d}^{h}+\pi_{d}^{i}-\tilde{\pi}_{d}^{i}\right)
$$

which is the increasing straight line that separates areas $(S)$ and $(T)$ in Figure 2.

For small values of the penalty $F_{t}$, the patentholder prefers to renounce and let the imitator remain in the market because dissuasion is by all means too costly. For high $F_{t}$, the patentholder has to decide whether to negotiate or to sue taking into account the cost of the settlement process. As long as $F_{s}$ is not too high, the incumbent prefers to negotiate with the infringer rather than going to court. This is explained by the cost associated with a trial that is internalized by the bargaining decision.

The exact location of these frontiers is obviously determined by the whole set of parameters of the model. We relegate to section 4.3 the analysis of how the frontiers shift when parameters change.

For each of the three final outcomes, which are assumed to be known by both players, ${ }^{15}$ we now study the simultaneous first stage game where the patentholder chooses the level of his monitoring effort before observing if entry did occur and the imitator decides whether to enter without knowing the decision of the patentholder. In section 5 we will consider the game where the entrant knows the monitoring effort of the patentholder before taking the decision of entry and symmetrically the game where the patentholder launches on an identification campaign upon observing a decrease in his profits.

\footnotetext{
${ }^{15}$ This is a drastic hypothesis. It would be obviously more realistic to suppose for instance that bargaining positions are private information. Several papers analyze how asymmetric information can explain failure to settle. See for instance Hay (1995). Likewise, in Meurer (1989), the incumbent has private information on the validity of his patent.
} 


\section{Entry and Monitoring in the Simultaneous Game}

\subsection{Equilibria Determination}

The imitator decides whether to enter without observing the incumbent's monitoring effort and the patent owner does not know if an imitator is in the market at the time of launching his surveillance program. In this framework, the equilibrium concept to use is the Nash equilibrium. A strategy of player $h$ is $x \in[0, \bar{x}]$ and a strategy of player $i$ is $e=[0,1]$. Denote by $x(e)$ the best response function of $h$ and by $e(x)$ the best response function of $i$. A Nash equilibrium is a pair of strategies $\left(x^{n}, e^{n}\right)$ such that $x\left(e^{n}\right)=x^{n}$ and $e\left(x^{n}\right)=e^{n}$.

First, note that whatever the final stage of the post-entry game (no identification, renunciation, trial or settlement), the payoffs when the imitator decides to stay out are the pair $\left(\pi_{m}^{h}-x, 0\right)$ since we have normalized the no-entry benefits of the challenger to 0 and the patentholder remains a monopoly after spending $x$. Consequently, we can directly deduce that $x(0)=0$. Without entry, the best choice of the patentholder is to spend nothing.

We now consider the equilibrium corresponding to the three alternative final outcomes that follow the identification of an entrant.

\section{Renunciation Solution}

When the incumbent is ready to accommodate entry, the payoff of the entrant is $\pi_{d}^{i}$, to be compared with 0 if she remains outside. We deduce that $\forall x, e(x)=1$; that is entry is a dominant strategy. When entry occurs, the payoff of the patentholder is simply $\pi_{d}^{h}-x$ which is obviously maximized at $x=0$. Then $x(1)=0$ and since we already know that $x(0)=0$, we can deduce that zero monitoring expenditure is a dominant strategy. Consequently, we can assert the following:

Proposition 2 In the simultaneous game, when the post entry solution is to accept infringement, there exists an equilibrium in dominant strategies where the patentholder does not spend anything and the imitator enters: ${ }^{16}$

$$
x^{n}=\underline{0} \quad, \quad e^{n}=\underline{1} .
$$

\footnotetext{
${ }^{16}$ Underlined symbols denote a dominant strategy.
} 
This outcome is an equilibrium in markets where the patentholder considers it worthless to deter entry. It can be either because a trial offers very little chance of winning any positive net compensation $^{17}$ or because the patent protects a weak innovation for which any license agreement would cost more than the expected royalties. ${ }^{18}$

\section{Trial Solution}

Assume now that the challenger is sure to be sued if the incumbent can identify her. When there is entry, the expected net profit of the entrant is ${ }^{19}$

$$
G_{t}^{i}(x)=p(x)\left[\widetilde{\pi}_{d}^{i}-F_{t}\right]+(1-p(x)) \pi_{d}^{i}
$$

since she will be sued and found guilty with probability $p(x)$ and she will remain unpunished with probability $1-p(x)$. This profit has to be compared with 0 obtained when staying outside. Assume there exists a value $\tilde{x}_{t}$ such that $G_{t}^{i}\left(\tilde{x}_{t}\right)=0$. Since $\frac{d G_{t}^{i}(x)}{d x}=p^{\prime}(x)\left[\widetilde{\pi}_{d}^{i}-F_{t}-\pi_{d}^{i}\right]<0$, as long as $x<\tilde{x}_{t}$ the risk of being identified and sued is so low that entry is profitable. By contrast, no entry is the best choice for $x>\tilde{x}_{t}$. As shown in Figure 1a, we conclude that the best response function of the entrant is

$$
e(x)=\left\{\begin{array}{l}
0 \text { if } x \geq \tilde{x}_{t} \\
1 \text { otherwise }
\end{array}\right.
$$

Note that if the penalty $F_{t}$ is very high, $G_{t}^{i}(0)<0$. This means that entry is not profitable even with no monitoring since $p(0)>0$ makes it possible to be identified and prosecuted. If, on the contrary, $\tilde{\pi}_{d}^{i}-F_{t}$ is positive, we obtain $G_{t}^{i}(\bar{x})>0$, which means that entry is profitable even when the infringer is sure to be fined (recall that $p(\bar{x})=1$ ).

Concerning the patentholder, his profits are

$$
G_{t}^{h}(x)=p(x)\left[\widetilde{\pi}_{d}^{h}+\alpha F_{t}\right]+[1-p(x)] \pi_{d}^{h}-x .
$$

\footnotetext{
${ }^{17}$ China, India and Japan are well known for their numerous patent infringers and counterfeiters encouraged by the free-and-easy attitude of the authorities with regards to intellectual property. "Flimsy, almost non-existent, patent laws have allowed [the 23,000 Indian drug companies] to flout Western norms of intellectual property." (Financial Times, May 24, 2000).

18 "Only $10 \%$ of the 55,000 brand new products that were launched globally last year are really innovative." The Economist, October 30th 1999, p. 85.

${ }^{19}$ In an intertemporal setting where the infringer enters at time 0 while the patent is active until time 1 , the expected (non discounted) profit of the entrant would be $(1-E \tau)\left[\widetilde{\pi}_{d}^{i}-F_{t}\right]+E \tau \pi_{d}^{i}$. The value $E \tau$ is the expected date of identification of the entrant with $\frac{\partial E \tau}{\partial x}<0$. This intertemporal setting is isomorphic to our static setting as long as all payoffs and costs are stationary flows.
} 
If $\frac{d G_{t}^{h}(0)}{d x}>0$ and $\frac{d G_{t}^{h}(\bar{x})}{d x}<0$, since $p^{\prime \prime}(x)<0$ there exists a value of $x$, namely $x_{t}^{*}$, strictly positive and less than $\bar{x}$ such that $\frac{d G_{t}^{h}\left(x_{t}^{*}\right)}{d x}=0$ (see Figure 1b). If $G_{t}^{h}\left(x_{t}^{*}\right)>0, x_{t}^{*}>0$ is the best monitoring decision. If $\frac{d G_{t}^{h}(0)}{d x}<0$, any spending on monitoring decreases profits so that $x_{t}^{*}=0$. If $\frac{d G_{t}^{h}(\bar{x})}{d x}>0$, the best choice is $x_{t}^{*}=\bar{x}$ provided that $G_{t}^{h}(\bar{x})>0$. This means that the best response to entry is ${ }^{20} x(1)=x_{t}^{*} \in[0, \bar{x}]$ and we know that $x(0)=0$.

It follows that the complete setting of the Nash equilibrium needs a comparison of $\tilde{x}_{t}$ (the threshold of monitoring expenditures that deters entry) and $x_{t}^{*}$ (the patentholder's best choice when there is entry).

\section{insert Figure 1}

- If $G_{t}^{i}(\bar{x}) \geq 0$, entry is a dominant strategy and the patentholder spends $x_{t}^{*}$ which can be a value between 0 and $\bar{x}$, as well as 0 or $\bar{x}$ if this is the best way for the patentholder to maximize his expected reward from a trial.

- Conversely, if $G_{t}^{i}(0) \leq 0$, entry would be a bad decision for any level of monitoring effort. Facing the no entry dominant strategy, the patentholder decides to spend 0 .

- The problem is more complicated when $G_{t}^{i}(0)>0>G_{t}^{i}(\bar{x})$. Suppose first that $x_{t}^{*}<\tilde{x}_{t}$. It results that $G_{t}^{i}\left(x_{t}^{*}\right)>0$ so that we obtain an equilibrium with entry despite the monitoring effort of the incumbent. In other words, from the best response functions

$$
x(e)=\left\{\begin{array}{l}
0 \text { if } e=0 \\
x_{t}^{*} \text { otherwise }
\end{array} \quad \text { and } \quad e(x)= \begin{cases}0 & \text { if } x \geq \tilde{x}_{t} \\
1 & \text { otherwise }\end{cases}\right.
$$

we conclude that the Nash equilibrium is $x^{n}=x_{t}^{*}$, and $e^{n}=1$.

Consider on the contrary the case where $x_{t}^{*}>\tilde{x}_{t}$ as in Figures 1a and 1b. Since $G_{t}^{i}\left(x_{t}^{*}\right)<$ $G_{t}^{i}\left(\tilde{x}_{t}\right)=0$, the best response of the challenger to the effort $x_{t}^{*}$ is to stay out (point $A$ ). But when the challenger is out, $x_{t}=0$ is the best choice of the incumbent (point $D$ ). And since we are in the case where $G_{t}^{i}(0)>0$, no monitoring encourages entry (point $C$ ) which, in turn, triggers a positive monitoring effort $x_{t}^{*}$ (point $B$ ). Consequently it appears that there is no Nash equilibrium in pure strategies.

But we can determine equilibria in mixed strategies. For example, if the patentholder spends

\footnotetext{
${ }^{20}$ Note that at $x_{t}^{*}$ the second order condition $d^{2} G_{t}^{h} / d x^{2}<0$ is satisfied since, in the "trial zone", it is true that $\tilde{\pi}_{d}^{h}+\alpha F_{t}>\pi_{d}^{h}$
} 
$\tilde{x}_{t}$ (which can be viewed as a degenerate mixed strategy), the challenger is indifferent between entering and not entering. If she chooses to enter with probability $\left[1+d G_{t}^{h}\left(\tilde{x}_{t}\right) / d x\right]^{-1}$, it is easy to check that $\tilde{x}_{t}$ is the best choice for the patentholder.

Another equilibrium is such that the patentholder draws randomly between $x_{t}=0$ and $x_{t}=$ $x_{t}^{*}$. In this equilibrium, $\left.i\right)$ the infringer enters with probability $x_{t}^{*} /\left[G_{t}^{h}\left(x_{t}^{*}\right)+x_{t}^{*}-G_{t}^{h}(0)\right]$ and $\left.i i\right)$ the patentholder decides a zero level of enquiry with probability $G_{t}^{i}\left(x_{t}^{*}\right) /\left[G_{t}^{i}\left(x_{t}^{*}\right)-G_{t}^{i}(0)\right]$ and spends $x_{t}^{*}$ with the complementary probability. Whatever the exact value of the probability of entry, the only thing that matters is that neither entry nor no-entry occur with certainty.

These results are summarized in Proposition 3.

Proposition 3 In the simultaneous game, when the post entry solution is to sue the infringer at law,

(a) if $G_{t}^{i}(\bar{x}) \geq 0$, there exists a Nash equilibrium in pure strategies $x^{n}=x_{t}^{*}, e^{n}=\underline{1}$,

(b) if $G_{t}^{i}(0) \leq 0$, there exists a Nash equilibrium in pure strategies $x^{n}=0, e^{n}=\underline{0}$,

(c) if $G_{t}^{i}(0)>0>G_{t}^{i}(\bar{x})$, either $x_{t}^{*} \leq \tilde{x}_{t}$ and there exists a Nash equilibrium in pure strategies $x^{n}=x_{t}^{*}, e^{n}=1$, or $x_{t}^{*}>\tilde{x}_{t}$ and there exist Nash equilibria in mixed strategies where the patentholder monitors his market with a probability smaller or equal to 1 and the infringer enters with a probability strictly smaller than 1.

\section{Settlement Solution}

In the "settlement outcome", the net profits are respectively

$$
G_{s}^{h}(x)=p(x)\left(\Pi^{h}-F_{s}\right)+(1-p(x)) \pi_{d}^{h}-x
$$

for the patentholder, and

$$
G_{s}^{i}(x)=p(x) \Pi^{i}+(1-p(x)) \pi_{d}^{i}
$$

for the entrant, where $\Pi^{h}$ and $\Pi^{i}$ are defined in (2) and (3) respectively.

As the problem is similar to the preceding one, using obvious notations we can directly assert the following: 
Proposition 4 In the simultaneous game, when the post entry solution is to come to arrangement with the infringer,

(a) if $G_{s}^{i}(\bar{x}) \geq 0$ there exists a Nash equilibrium in pure strategies $x^{n}=x_{s}^{*}$, $e^{n}=\underline{1}$,

(b) if $G_{s}^{i}(0) \leq 0$ there exists a Nash equilibrium in pure strategies $x^{n}=0, e^{n}=\underline{0}$,

(c) if $G_{s}^{i}(0)>0>G_{s}^{i}(\bar{x})$, either $x_{s}^{*} \leq \widetilde{x}_{s}$ and there exists a Nash equilibrium in pure strategies $x^{n}=x_{s}^{*}, e^{n}=1$ or $x_{s}^{*}>\tilde{x}_{s}$ and there exist Nash equilibria in mixed strategies where the patentholder monitors his market with a probability smaller or equal to 1 and the infringer enters with a probability strictly smaller than 1.

Whether the patentholder decides to go to court or to settle an agreement we find different kinds of equilibria depending on the expected payoff of the imitator. In type (a) equilibria, it is always worthwhile for the imitator to enter the market, either because the expected fine she will have to pay if her identity is discovered is not too high, or the probability of being identified is low. The patentholder monitors the market, but cannot prevent entry. The probability of being identified will be low if the infringed patent is in an area far away from the infringer's product.

The opposite arises in type (b) equilibria. Here, it is not worthwhile at all for the imitator to enter the market. It is essentially because the imitator knows that if she is discovered (and the probability of being discovered is very high), the expected penalty will be harmful. The patentholder does not need to monitor. This would be the case of a small infringer against a big tough patentholder. We can also think of pharmaceutical patents in Western countries. ${ }^{21}$ In this industry, patents protect innovations that have been very costly to obtain and that promise high returns. Because going through clinical trials and administrative approval is lengthy and can be verified easily, pure imitation is easy to detect and to prove. It results that patent challenges on drugs are less frequent than in other areas (2 trials for 100 patents against 6 for 100 in all areas (Lanjouw, 1993)).

In case (c), the potential imitator has no dominant strategy. When the patent owner is not ready to spend much on monitoring $\left(x_{j}^{*}<\tilde{x}_{j}, j=s\right.$ or $\left.t\right)$, the equilibrium path is the same as

\footnotetext{
${ }^{21}$ It also begins to be true in less developed countries: "Under threat from the World Trade Organization, India has agreed to recognize pharmaceutical patents by 2005. (...). "We are all in favor of intellectual property rights," says the medical director of an Indian drug company. "Not just to protect our discoveries from multinationals, but from each other"." Financial Times, May 24, 2000.
} 
in case (a). In the opposite case when both firms play randomly, any of the four non-equilibrium outcomes depicted as points $A, B, C$ and $D$ in Figures $1 \mathrm{a}$ and $1 \mathrm{~b}$ can occur. This does not facilitate the task of interpreting data on patent cases.

\subsection{Graphical Illustration}

The various equilibria of the former section can be charted with respect to several sets of parameters. We have chosen a presentation in terms of the following pair of parameters: the fine charged to the infringer in case of a finding of infringement $F_{t}$ and the cost to launch on a settlement round $F_{s}$. These are one of the "four key determinants of the likelihood of observing a filed case" (Lanjouw and Schankerman, 1998). The three other ones are the likelihood of a potentially litigious situation, a divergence in the parties' expectations regarding their chances of prevailing at trail and the expectation of the stakes.

Depending on the values of $F_{t}$ and $F_{s}$, we analyze the equilibria of propositions 2,3 and 4 within each of the three areas of Figure 2 described in section 3.

insert Figure 2

(i) In the left part of the figure, where the final outcome is "no reaction by the patent owner", we have the simplest type of equilibrium: equilibrium in dominant strategies where the incumbent spends nothing to monitor his market and the imitator enters. This pair of decisions needs no strategic reasoning by players: it is only based on the very low observed or expected value of the fines in case of infringement $F_{t}$. The obvious question is why the innovator has paid for a patent if he is not ready to defend it against violators. This question is to be asked before our story begins. Actually, even though some recent econometric studies show that an increasing number of innovators worry about litigation cost before patenting (Lerner, 1995), we observe as a stylized fact that many innovators apply for a patent without exploring the future costs of legal protection. This is especially true for small firms that are short in cash and are unable to sue infringers. It can also be the case of big firms that do not have a rigorous patent policy. "Xerox owned some 8,000 patents (in 1997). Some of its patented technologies were being illegally copied by other companies, but no steps were taken to detect and stop such patent infringement." (Rivette and Kline, 2000).

(ii) In zones $(S)$ and $(T)$ we have a larger spectrum of equilibria. Consider first the trial zone, that is the upper part on the right of Figure 2. By proposition 3, we have to distinguish three 
equilibria.

(a) When $G_{t}^{i}(\bar{x}) \geq 0$, that is by (6) when $F_{t} \leq \tilde{\pi}_{d}^{i}$, entry is a dominant strategy for the imitator, and the incumbent does not have a dominant strategy but, knowing the challenger's decision, his best choice is to spend $x_{t}^{*}$ on monitoring.

(b) Symmetrically, when $G_{t}^{i}(0) \leq 0$, i.e. when $F_{t} \geq \tilde{\pi}_{d}^{i}+\frac{1-p(0)}{p(0)} \pi_{d}^{i}$, the expected profits of the entrant are negative whatever the monitoring effort of the patentee. Consequently, the challenger's decision to stay out is dominant and the incumbent can infer that his best choice is to spend nothing.

(c) We examine now part (c) of proposition 3. Assuming that $x_{t}^{*}$ is an internal solution, it is defined by

$$
p^{\prime}\left(x_{t}^{*}\right)\left[\widetilde{\pi}_{d}^{h}+\alpha F_{t}-\pi_{d}^{h}\right]-1=0
$$

where the expression in brackets is positive as long as we are in the lawsuit zone. Consequently, it is easy to check that $\frac{d x_{t}^{*}}{d F_{t}}>0$. The higher the fine for infringement, the greater the optimal monitoring expenses of the patentholder.

By contrast, we know that the monitoring expenditures that dissuade entry are $\tilde{x}_{t}$ defined by

$$
p\left(\tilde{x}_{t}\right)\left[\tilde{\pi}_{d}^{i}-F_{t}-\pi_{d}^{i}\right]+\pi_{d}^{i}=0
$$

where the expression in brackets is negative. It follows that $\frac{d \tilde{x}_{t}}{d F_{t}}<0$. The expenditures that deter entry are lower when the fine is high.

Consequently, we can say that $x_{t}^{*}<\tilde{x}_{t}$ (respectively $x_{t}^{*}>\tilde{x}_{t}$ ) for low (resp. high) values of $F_{t}$. Note also that the above expressions do not depend on $F_{s}$. Then, using proposition $3(\mathrm{c})$, we can conclude that for $\tilde{\pi}_{d}^{i} \leq F_{t} \leq \tilde{\pi}_{d}^{i}+\frac{1-p(0)}{p(0)} \pi_{d}^{i}$, there exists a vertical frontier between

- on the left, Nash equilibria in pure strategies $e^{n}=1, x^{n}=x_{t}^{*}$ and,

- on the right, Nash equilibria in mixed strategies.

(iii) In the lower part of Figure 2, players know that the final outcome will be to settle.

(a) Using proposition 4 , if $G_{s}^{i}(\bar{x}) \geq 0$, that is if

$$
F_{t} \leq \dot{F} \stackrel{\text { def }}{=} \frac{\rho \widetilde{\pi}_{d}^{i}+(1-\rho)\left(\pi_{d}^{i}+\pi_{d}^{h}-\widetilde{\pi}_{d}^{h}\right)}{\rho+(1-\rho) \alpha},
$$


entry is a dominant strategy, which provokes expenditures $x^{n}=x_{s}^{*}$ by the patentee. It is easy to check that $\dot{F} \geq \tilde{\pi}_{d}^{i}$ and the equality holds only when the incumbent has the whole bargaining power $(\rho=1)$. We can infer that entry is more likely to happen in the settlement zone than in the trial zone, as long as the imitator is able to resist the incumbent $(1-\rho>0)$.

(b) By proposition 4(b), no entry is a dominant strategy, and consequently $x^{n}=0$ is the incumbent's best choice when $G_{s}^{i}(0) \leq 0$, that is when

$$
F_{t} \geq \ddot{F} \stackrel{\text { def }}{=} \frac{\rho \widetilde{\pi}_{d}^{i}+(1-\rho)\left(\pi_{d}^{i}+\pi_{d}^{h}-\tilde{\pi}_{d}^{h}\right)+\frac{1-p(0)}{p(0)} \pi_{d}^{i}}{\rho+(1-\rho) \alpha} .
$$

Since $\ddot{F} \geq \widetilde{\pi}_{d}^{i}+\frac{1-p(0)}{p(0)} \pi_{d}^{i}$ and the equality holds only for $\rho=1$, we can also infer that no entry is dominant in the settlement zone less often than in the trial zone as long as the imitator has some negotiation power.

(c) It remains to examine what occurs for $\dot{F}<F_{t}<\ddot{F}$, that is when Proposition 4(c) holds. Using the same argument as in paragraph (ii-c) above, it is easy to prove that $\frac{d x_{s}^{*}}{d F_{t}}>0>\frac{d \tilde{x}_{s}}{d F_{t}}$, so that we will have Nash equilibria in pure strategies $\left(e^{n}=1, x^{n}=x_{s}^{*}\right)$ for low values of $F_{t}$ and Nash equilibria in mixed strategies for higher values of $F_{t}$. Nevertheless, there is a difference with the trial zone. Here, $x_{s}^{*}$ is a function of $F_{s}$ $\left(\frac{d x_{s}^{*}}{d F_{s}}<0\right)$, while $\tilde{x}_{s}$ is not affected by changes in $F_{s}$. Consequently, the set of pairs $\left(F_{t}, F_{s}\right)$ such that $x_{s}^{*}=\tilde{x}_{s}$ gives an increasing function. The proof is as follows. Let $x_{s}^{*}=f^{*}\left(F_{t}, F_{s}\right)$ and $\tilde{x}_{s}=\tilde{f}\left(F_{t}\right)$. It is easy to check that $\partial f^{*} / \partial F_{t}>0, \partial f^{*} / \partial F_{s}<0$ and $d \tilde{f} / d F_{t}<0$. Consequently, total differentiation of the frontier $x_{s}^{*}=\tilde{x}_{s}$ gives $d F_{s} / d F_{t}>0$.

\subsection{Infringement Incentive and Disincentive}

$>$ From the observation of Figure 2, one can deduce a series of corollaries to propositions 2, 3 and 4. We will successively consider the effect on entry of a change in $(i)$ the penalty for infringement, (ii) the cost of launching a settlement round, (iii) the fraction of the penalty received by the patentholder, $(i v)$ the bargaining power of the patentholder, $(v)$ the efficiency of the monitoring process and $(v i)$ the profit differentials.

Corollary 1 The frequency of entry is usually decreasing with the amount of the penalty for infringement. However this relation can be locally non-monotonic. 
It is obvious from Figure 2 that when $F_{s}$ is either very high or very low, an increase in $F_{t}$ has the expected effect of decreasing the likelihood of entry. Nevertheless, for intermediate values of $F_{s}$, one can find several cases of non monotonicity due to the final options $(R),(S)$ and $(T)$ for the patentholder. Consider for example an increase of the fine from $X_{t}$ to $Y_{t}$, and then from $Y_{t}$ to $Z$ in Figure 2. At $X_{t}$ the probability of entry is 1 , it is less than 1 at $Y_{t}$, and it increases back to 1 at point $Z$. We see that a higher penalty increases (locally) the likelihood of entry. Indeed, while at point $Y_{t}$ the imitator hesitates to enter (plays randomly), at point $Z$ negotiation allows to avoid judicial expenditures for both. A necessary condition is that an increase in $F_{t}$ provokes a switch from area $(T)$ to area $(S)$ where entry is more frequent. For this to be true, the frontier between $(T)$ and $(S)$ must be strictly increasing. From equation (5), we must have $\rho>0$ and $\alpha<1$. Indeed, without any negotiation power the patentholder would never propose to settle, and when the difference between the penalty and the compensation is high, both parties are better off out of court.

Corollary 2 The frequency of entry is usually decreasing with the settlement cost. However this relation can be locally non-monotonic.

The first part comes from the fact that the higher the settlement cost, the higher the probability of a trial, and this reduces the incentive to enter. Concerning the second part, we can observe that when the final outcome is to settle and $F_{s}$ increases, the patentholder is less willing to invest in supervision. With a lower probability to be identified, the infringer is more inclined to enter as it can been seen by moving from point $X_{s}$ to point $Z$ in Figure 2.

Corollary 3 The frequency of entry decreases when justice becomes more efficient.

When the fraction of the penalty paid by the imitator and transferred to the patentholder increases, using (4) and (5), we see that the trial area spreads out both because the eastern frontier of $(R)$ moves to the left and the frontier between $(T)$ and $(S)$ shifts downward. Actually, the imitator's gain in case of settlement becomes smaller because the patentholder has a higher reservation utility due to the trial threat and thus he can impose a higher licence fee. But because the frontier between $(R)$ and $(S)$ also moves to the left, the net effect of a more efficient justice system ( $\alpha$ closer to 
1) on the likelihood of a settlement outcome can be positive or negative. Within each zone, the likelihood of each type of equilibrium is also affected. For example, when $\alpha$ increases, $\dot{F}$ and $\ddot{F}$ move leftward, hereby decreasing the probability of entry in the settlement zone. In the trial zone, as the eastern frontier of the equilibrium $\left(e^{n}=\underline{1}, x^{n}=x_{t}^{*}\right)$ is fixed at $\widetilde{\pi}_{d}^{i}$, a decrease in $\alpha$ means a progressive vanishing of this zone, followed by the central one, and so on.

Corollary 4 The frequency of entry can increase or decrease with the bargaining power of the patentholder.

An increase in $\rho$ has two effects. First, it expands the settlement area (see (5)). Indeed, with a higher negotiation power, the patentee can impose a higher licence fee and then prefers to negotiate instead of going to court. If this first effect provokes a switch of the equilibrium from $(T)$ to $(S)$, it induces an increase in the probability of entry. The second effect is that, within area $(S)$, because the entrant will have to pay a higher licence, she has less incentive to enter.

Corollary 5 The frequency of entry decreases with the probability of identification.

When $p(0)$ increases, the areas $(R),(S)$ and $(T)$ are not affected whereas the frontiers of the areas where the equilibrium consists in no entry moves leftward. It results that entry will occur less frequently. A high $p(0)$ can be interpreted as the monitoring of a narrow patent. In this case, any entrant is easy to identify, while for wide patents (in a geographical or industrial sense) the identification of an infringer is probably more costly.

Corollary 6 The frequency of entry increases with the profit differentials.

When the imitator enters with a highly differentiated product, for both firms $(k=h, i)$ the duopoly profits $\pi_{d}^{k}$ are very large. One effect is to increase the renunciation area and to decrease the trial area which induces more entry. Moreover, within $(S)$ and $(T)$, the frontier between each type of equilibria moves to the right which gives an additional incentive to enter. To enter with a differentiated product allows to limit the risks of being condemned or having to pay a licence fee. 
One can also use Figure 2 to explain the decision of large drug companies to abandon pursuits against the government of South Africa in March 2001. ${ }^{22}$ At the date they launched the lawsuit for patent infringement, the value of parameters resulted in what they thought to be an equilibrium in region $(T)$. But under the pressure of international opinion and the action of non governmental organizations, the drug companies eventually computed that $\widetilde{\pi}_{d}^{h}$ could be much lower than expected. This means a much wider $(R)$ zone as well as a higher frontier between $(S)$ and $(T)$. After revision of their forecast the firms realized they were playing in the renunciation area. Consequently they decided $(i)$ to give up court actions and (ii) to cut their prices at the level of generics.

\section{The sequential games}

Instead of supposing that the entry decision and the monitoring expenditures are chosen without knowing the decision of the other agent, we can consider situations in which the agents play sequentially, the second knowing the decision of the first one. Two sequential games can be analyzed. In the first one, the entrant observes the value of $x$ and consequently knows the probability of being identified before entering. This is not very different from standard entry deterrence games (see Dixit, 1980). In the second game, by contrast, the patentholder decides how much to spend on monitoring after he has detected entry. We consider how these alternative scenarios change the results of the preceding model.

\subsection{The patentholder plays first}

The pertinent notion of equilibrium is now the perfect equilibrium. The patentholder chooses $x \in[0, \bar{x}]$ and, observing $x$, the entrant takes a decision conditional on $x$ : her best choice is a function $e(\cdot)$ mapping the segment $[0, \bar{x}]$ into the binary set $\{0,1\}$.

As compared with the simultaneous game, the main difference is that $\tilde{x}_{t}$ (in the trial sub-game) or $\tilde{x}_{s}$ (in the settlement sub-game) is now an essential strategy for the patentholder. Indeed, in the simultaneous case for $G_{j}^{i}(0)>0>G_{j}^{i}(\bar{x})$ (where $j$ stands for $s$ or $t$ ) entry could be deterred only as a lucky by-product of the decision to maximize the incumbent's expected profits. At the same time that the incumbent was randomly selecting his supervision effort, the challenger was randomizing over whether or not to stay out of the market. By contrast, now the patentholder can set his expenditures voluntarily at the value $\tilde{x}_{j}$ with the expected consequence of deterring entry.

\footnotetext{
${ }^{22}$ For details, see for instance The Economist, March 8th 2001.
} 
Then, knowing the reaction function

$$
e(x)= \begin{cases}0 & \text { if } \quad x \geq \tilde{x}_{j} \quad j=s, t \\ 1 & \text { otherwise }\end{cases}
$$

the incumbent chooses between $x_{j}^{*}$ that maximizes the post entry profit $G_{j}^{h}(x)$ and $\tilde{x}_{j}$ that gives $\operatorname{him} \pi_{m}^{h}-\tilde{x}_{j}$ since entry is deterred.

Suppose first that $\tilde{x}_{j}<x_{j}^{*}$ as in Figures 1a and 1b. Consequently, $\pi_{m}^{h}-\tilde{x}_{j}>\pi_{m}^{h}-x_{j}^{*}>$ $p\left(x_{j}^{*}\right)\left[\widetilde{\pi}_{d}^{h}+\alpha F_{t}\right]+\left(1-p\left(x_{j}^{*}\right)\right) \pi_{d}^{h}-x_{j}^{*}$. It results that the Nash perfect equilibrium is

$$
x^{n p}=\tilde{x}_{j} \quad, \quad e^{n p}(x)= \begin{cases}0 & \text { if } x \geq \tilde{x}_{j} \\ 1 & \text { otherwise }\end{cases}
$$

and entry does not occur on the equilibrium path.

If, on the contrary, $\tilde{x}_{j}>x_{j}^{*}$, we can observe accommodated entry (when $G_{j}^{h}\left(x_{j}^{*}\right)>\pi_{m}^{h}-\tilde{x}_{j}$ ) or otherwise deterred entry as above. The fact that the patentholder accommodates entry does not mean that he will not react since with probability $p\left(x_{j}^{*}\right)$ the infringer will be prosecuted when $j=t$ or will produce under license and pay royalties when $j=s$.

When $G_{j}^{i}(0)<0$ or when $G_{j}^{i}(\bar{x})>0$, the game remains intrinsically identical to the simultaneous one since the entrant has a dominant strategy; no entry in the first case, entry in the second case, whatever the observed value of $x$. Consequently, we can state the following.

Proposition 5 When the monitoring expenditure is observed by the entrant before she takes her decision, the patentholder is more likely to deter entry than in the simultaneous game.

This commitment value of market watching can be implemented through advertising campaigns in professional newspapers or through public announcements about the establishment of an intelligence service. For instance in the biotechnology industry, big firms tend to monitor closely the progress of competitors (Lerner, 1995). Large expenses in monitoring can be viewed as an investment in reputation or a commitment to be tough when infringement occurs.

\subsection{The imitator plays first}

The perfect equilibrium is now made of a decision $e=\{0,1\}$ taken by the candidate for entry and a reaction function of the patentholder $x(\cdot)$, mapping the set $\{0,1\}$ into $[0, \bar{x}]$. When there is no 
entry, $x(0)=\arg \max _{x} \pi_{m}^{h}-x$ is obviously 0 . When there is entry the decision of the incumbent is $x(1)=\arg \max _{x} G_{j}^{h}(x)$ which is $x_{j}^{*}$ or, in case of corner solutions, 0 or $\bar{x}$.

It appears that now randomization is never necessary to obtain an equilibrium. Knowing the reaction function of the property right owner,

$$
x(e)= \begin{cases}0 & \text { if } \quad e=0 \\ x_{j}^{*} & \text { otherwise }\end{cases}
$$

the challenger has just to compare it with $\tilde{x}_{j}$. If $x_{j}^{*}<\tilde{x}_{j}$ she enters, and if $x_{j}^{*}>\tilde{x}_{j}$, she stays out of the market.

Proposition 6 When the monitoring expenditures are decided after an entry has been detected, the challenger is more likely to stay out than in the corresponding simultaneous game.

This result can be interpreted in the following way. In the sequential game where the patentholder takes an observable decision and in the simultaneous game, monitoring expenditures are actually two dimensional. On one hand, they are dissuasive since the challenger can anticipate the inconvenience of entry. On the other hand, they are punitive since they increase the chances to extract revenues from an infringer. By contrast, when monitoring is totally decided ex post, its only purpose is to improve the chances to compensate the patentholder. As the incumbent decides how much to spend only after observing entry, entry appears more costly than when the incumbent is a first or simultaneous mover.

We see that the main effect of sequentiality is to make the decisions of both players more efficient in the following sense. When playing first, the incumbent sends valuable information to the potential competitor, who can then avoid being trapped in a non-profitable lawsuit. When the challenger plays first, the patentholder can moderate his monitoring effort to an efficient repression or negotiation instead of spending resources in order to identify an entrant that, maybe, does not exist.

\section{Conclusion}

Patent protection is not perfect. It only grants the right to sue intruders if they have been identified. The patentholder has to monitor his protected market in order to detect and identify an infringer. Next he has to decide how to react to infringement. He may decide to go to court, to agree upon some kind of arrangement or to let the infringer remain in the market. In this paper we have 
investigated how intensive the monitoring effort should be and how a potential infringer should make her decision to enter. We have first considered a simultaneous game in which both the patentholder and the infringer take their monitoring and entry decision at the same time. Based on the values of the parameters, we have exhibited a variety of equilibria in dominant strategies, pure strategies or mixed strategies. In the analysis of the effects of changes in the parameter values on the entry decision, we have found some counter-intuitive results. For instance, the likelihood of entry can increase with the penalty. We also have considered two sequential games. In the first game, the patentholder chooses his monitoring effort before the imitator takes her entry decision. In the second game, the patentholder observes whether entry occurs and then decides how much to spend in monitoring. Entry occurs less often in these sequential games than in the corresponding simultaneous game.

The model can be improved on several grounds, in particular by the introduction of dynamics, uncertainty and / or asymmetric information. Uncertainty during the litigation process can be detrimental either for the patentholder or the infringer. Concerning asymmetric information between the players, one can think that the patentholder has better information concerning his patent as well as its weaknesses and strengths like in Meurer (1989). By contrast, the entrant may have private information regarding her cost and benefit from infringement. Asymmetric information can help to better explain why legal disputes go to trial instead of settling (Hay, 1995). Further developments of the model should include these assumptions as well as a dynamic framework in order to capture the flexibility of supervision decisions (expenditures are not totally sunk), memory effects (firms with large patent portfolios maintain data set on infringers) and reputation effects (to fight an entry that could be accommodated is an investment in reputation to be tough with future infringers).

\section{References}

Aoki, R. and J.L. Hu. (1999a) "Imperfect Patent Enforcement, Legal Rules and Settlement," Auckland Business School Working Paper.

Aoki, R. and J.L. Hu. (1999b) "A Cooperative Game Approach to Patent Litigation, Settlement, and Allocation of Legal Costs," Auckland Business School Working Paper 186 .

Aoki, R. and Y. Spiegel (2000) "Public Disclosure of Patent Applications, R\&D, and Welfare" W.P. Northwestern University, June. 
Choi, J.P. (1998) "Patent Litigation as an Information - Transmission Mechanism", American Economic Review, December, vol. 88 nº5, 1249-1263.

Cooter, R. and D. Rubinfeld (1989) "Economic Analysis of Legal Disputes and their Resolution", Journal of Economic Literature, 27, 1067-1097.

Crampes C. and C. Langinier (1998) "Information Disclosure in the Renewal of Patents", Annales d'Economie et de Statistique, 49/50, 266-288.

Dixit, A (1980) "The Role of Investment in Entry Deterrence", Economic Journal, 90, 95-106.

Gallini N. (1984) "Deterrence by Market Sharing: A Strategic Incentive for Licensing", The American Economic Review, 74, 931-941.

Gallini, N. (1992) "Patent Policy and Costly Imitation", Rand Journal of Economics, $23,52-63$.

Gilbert R. et C. Shapiro (1990) "Optimal patent length and breadth", Rand Journal of Economics, 21, 106-112.

Harhoff D. and M. Reitzig (2000) "Determinants of Opposition against EPO Patent Grants. The Case of Biotechnology and Pharmaceuticals", WP, Center for Economic Policy Research, London.

Hay, B.L. (1995) "Effort, Information, Settlement, Trial", Journal of Legal Studies, Vol. XXIV, January, 29-62.

Klemperer, P. (1990) "How broad should the scope of patent protection be ?", Rand Journal of Economics, 21, 113-130.

Lanjouw J. (1993) "Patent Protection: Of What Value and For How Long?", NBER, working paper \# 4475 .

Lanjouw J. and J. Lerner (1997) "The Enforcement of Intellectual Property Rights: a Survey of the Empirical Literature", NBER, working paper \# 6296.

Lanjouw J. and M. Schankerman (1998) "Stylized facts of Patent Litigation: Value, Scope and Ownership", WP., London School of Economics EI/20.

Lerner J. (1995) "Patenting in the Shadow of Competitors", Journal of Law and Economics, XXXVIII, p. 463-495. 
Marshall, R.C., M.J. Meurer and J.F. Richard (1994) "Litigation Settlement and Collusion", Quarterly Journal of Economics, February, 109(1), 211-239.

Meurer, M.J. (1989) "The Settlement of Patent Litigation", RAND Journal of Economics, Spring, 20(1), 77-91.

Pooley, J. (1999) "Putting together a Global Enforcement Solution", Managing Intellectual Property, November 1999, Issue 94, 16-19.

Reinganum, J.F. (1989) "The timing of innovation: research, development and diffusion" Chapter XIV, Handbook of Industrial Organization, vol.1, Ed. Schmalensee R. and R.D. Willig.

Rivette, K. and D. Kline (2000) Rembrandts in the Attic: Unlocking the Hidden Value of Patents, Harvard Business School Press.

Schankerman M. and S. Scotchmer (2001) "Damages and injunctions in protecting intellectual property", RAND Journal of Economics, vol. 32 n¹,Spring,199-220.

Silverman, A.B. (1992) "Patent Infringement. Is it Better to Fight or Switch?", JOM, $44(5)$, p. 66.

Warshofsky, F. (1994) The Patent Wars, John Wiley and Sons, New York. 
Figure 1a: Infringer's profit

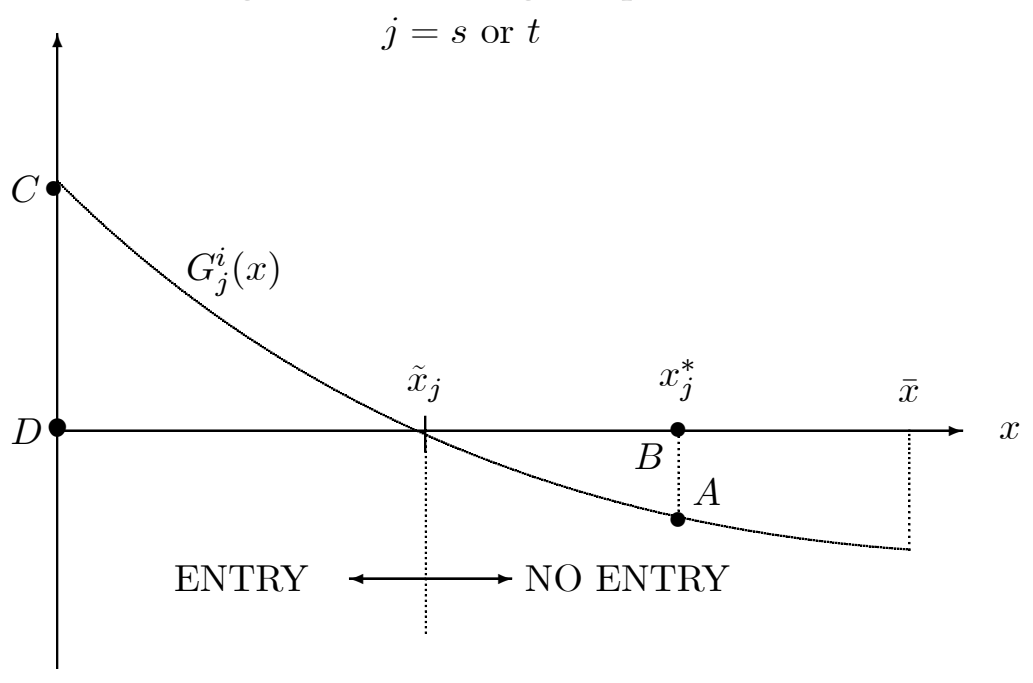

Figure 1b: Patent-holder's profit

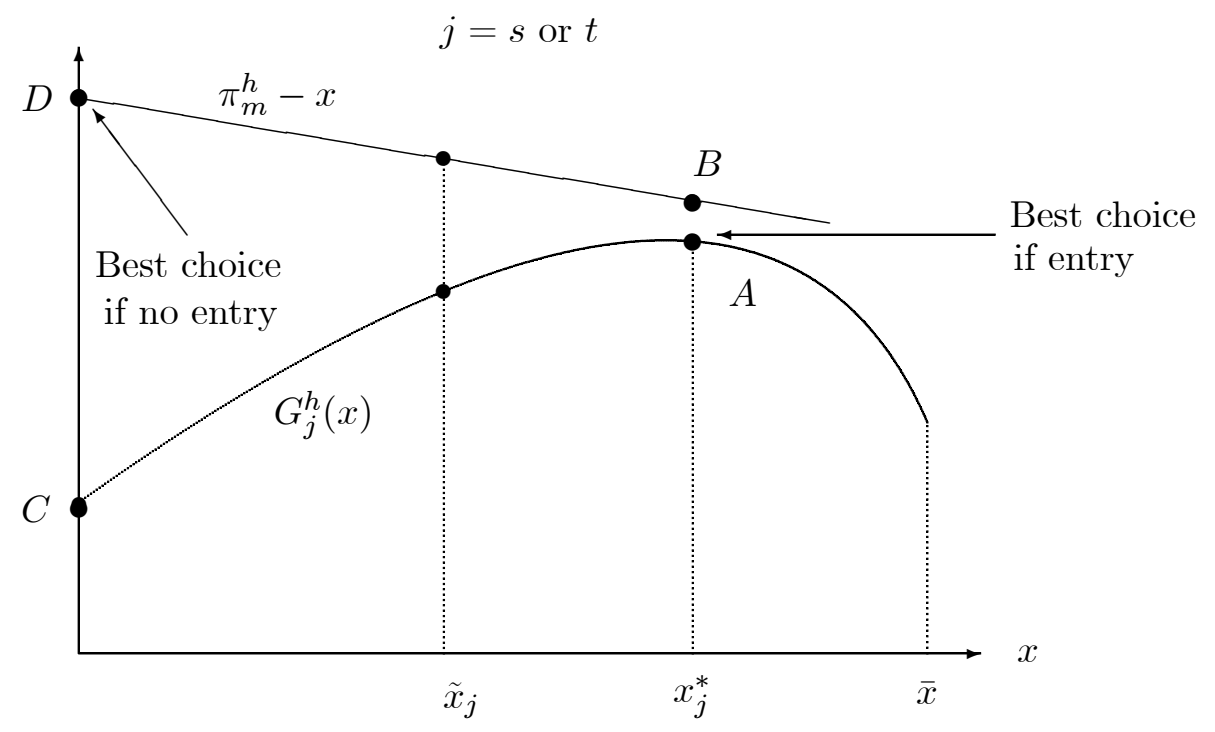




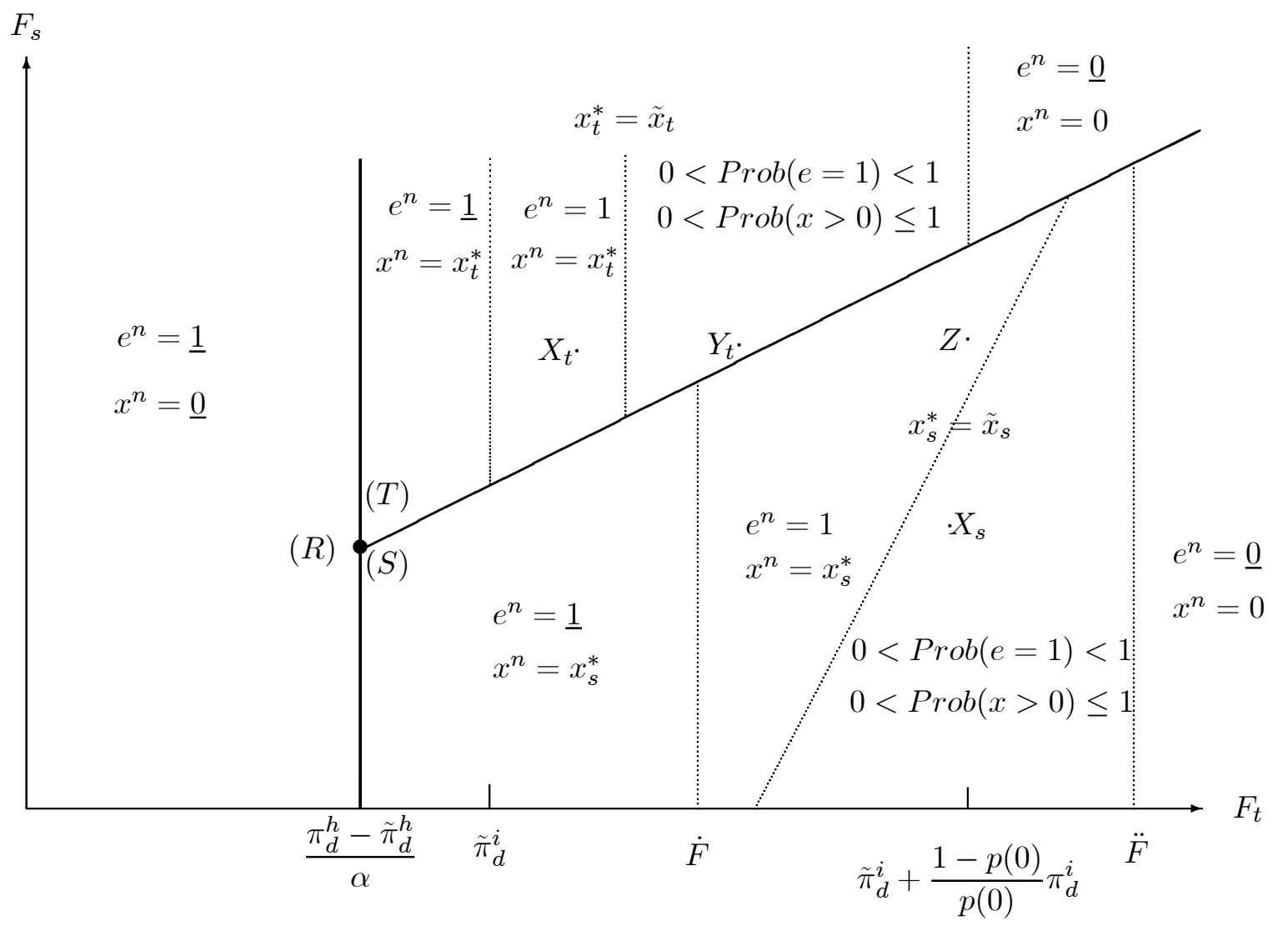

Figure 2: Different types of equilibria

(dominant strategies are underlined) 